\title{
INTERPROFESIONALNO OBRAZOVANJE U SRBIJI - POČETNI KORACI IMPLEMENTACIJE
}

Dragana Milutinović, Zoran Komazec², Dragana Simin', 1Univerzitet u Novom Sadu, Medicinski fakultet, Katedra za

zdravstvenu negu, 2 Univerzitet u Novom Sadu, Medicinski fakultet, Katedra za otorinolaringologiju

Korespodent:

Dragana Milutinović
e-mail: dragana.milutinovic@mf.uns.ac.rs

ružanje usluga u sistemu zdravstvene i socijalne zaštite danas je gotovo nezamislivo sa aspekta da jedna profesija sama moze odgovoriti i resiti brojne probleme koji pacijenti imaju, bilo da su u pitanju bolesna deca, povredeni adolescenti, disfunkcionalne porodice, osobe sa hronichim nezarazhim bolestima ils i lisciplina Postoji Z idsciplina. Postoji sve vece preklapanje znanja i vestina izmedu zdravstreniti često menjaju. različtih zdravstven grice koje defnisu uloge i odgovonosti razlicin z sinazo obra inje zro terprofesio

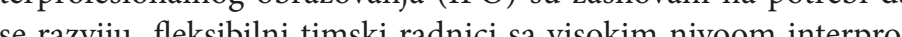
se razviju helsib profesija čini za čoveka i zdravlje [1-3].

Tog obrazovanja postoji mogućnost da se ,nešto slučajno" nauči o drugim profesijama. Zajednička predavanja se cešce primenjuju iz ekonomskih razloga, a ne obrazovnih principa. Prilkom ovakvih predavanja tipično je za studente da su pasivni primaoci znanja, a da je interaktivno ucenje svedeno na minim.

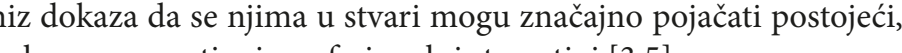
Razing

Razvijanje IPO u cilju poboljšanja interprofesionalne prakse je proces koji traje već skoro cetrdeset godina na međunarodnom ciji (3. SPO 1973. go dine u cilju boljeg i (SZO) je zapocela in-

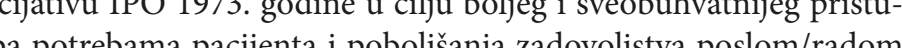
adrara a tradico zašiti. U dellaraciij Zdravlje za sve (Health for All) iz Alma Ate

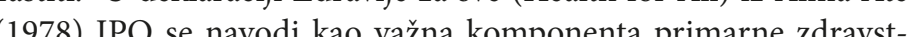
(1978) Irtite. Na ovu temu SZO 1988, godine publikje tehnick

Interprofesionalno obrazovanje (Interprofessional education) ima različita značenja u različitim kontekstima i diskusionim grupama. Definiciju koja se najčěšće koristi dao je Centar za unapredenje interprofesionalnog obrazovanja u Velikoj Britaniji (Cen-

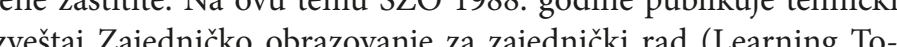
ether to Work Together), koji je os 6]. Publikacijom iz 2010, godi Je Fraver for Action On Interprofessiol Education Collabortive Practice donosicima odlu"Interprofesion sa drugima od drugih i o drugima da bi pobolišli mefusobnu saradnju i kvalitet zdravstvene zaštite". Pod interprofesionalnim obrazovanjem se podrazumeva sticanje obrazovanja u obrazovnim institucijama i radnoj sredini u oblastima zdravtvene i socijaln zaštitite, pre i po sticanju kvalifikacija/diplome [3-4].

Termin multiprofesionalno obrazovanje (Multiproffesional education) podrazumeva situacije u kojima dve ili više profesija uče zajedno bez namerne i sistematične interakcije (na primer, studenti različitih studijskih programa zajedno prisustvuju predavanjima) [1,3-5]. deje za implementaciju IPO [7].

Međunarodne organizacie kao što je Organizacija sa saradnju i razvoj (Organization for Economic Co-operation and Development, OECD) i Međunarodna federacija za medicinsko obrazovanje (World Federation of Medical Education, WFME) takode su usvojili i podržali ovu obrazovnu inicijativu. Medutim, razvoj IPO na nacionalnim nivoima je različit. U Evropi, pored Velike Britanije gde je National Health Service (NHS) 2001. godine naložio da IPO postane sastavni deo obrazovanja svih zdravstvenih ložio da (Finska, Švedska, Norveška) [3-4,7]. 
Implementacija interprofesionalnog obrazovanja u obrazovne i ustanove zdravstvene i socijalne zaštite je složeno. Različiti studijski programi, stručnjaci različitih profesija unutar kojih su i mnoge discipline, razne političke, obrazovne i društvene organizicije učestvuju u uvođenju, primeni i evaluaciji svih novih obrazovnih strategija obrazovanja (Slika 1) [8]. Od svih elemenata prikazani nog obarazovanja: studenti, nastavnici i institucije [9].

Slika 1. Sistem implementacije interprofesionalnog obrazovanja

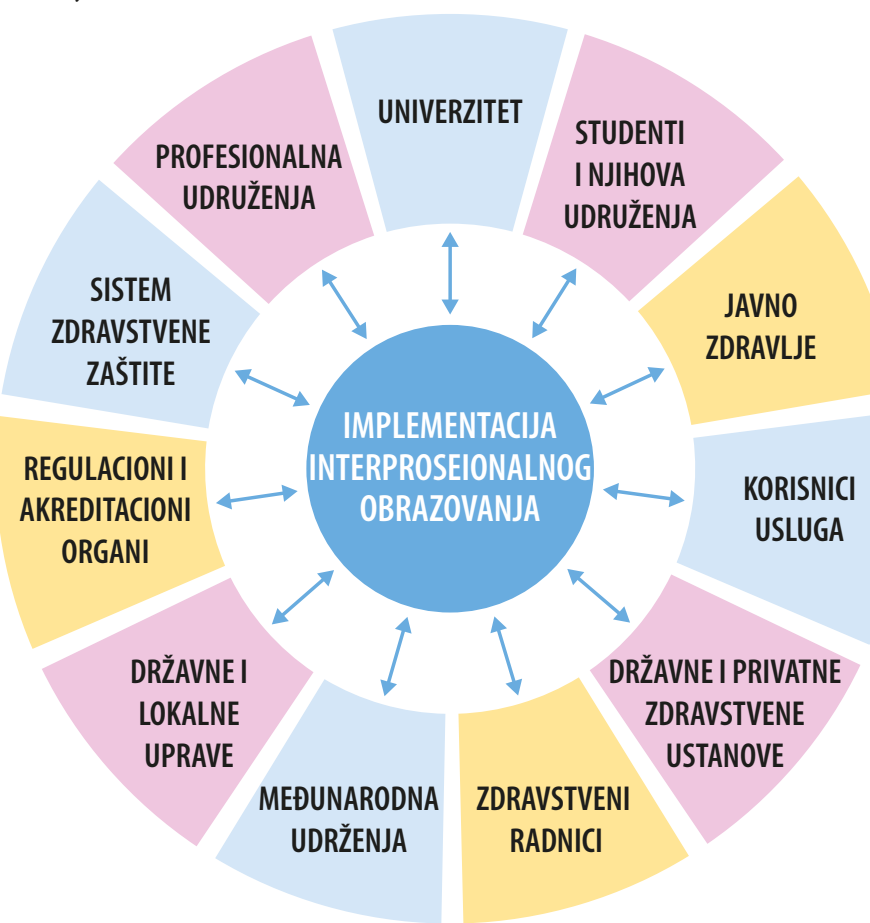

Primena IPO kao obrazovne strategije u Republici Srbij započeta je u okviru Erasmust projekta pod nazivom Reinforcement of the Framework for Experiential Education in Healthcar in Serbia (ReFEEHS), ciji nosilac je Univerzitet u Beogradu.

$U$ okviru pripremnih aktivnosti za implementaciju IPO planiranih ReFEEHS projektom, održano je više skupova i tematski radionica. Prve IPO radionice u Srbiji realizovane su u okvir Simpozijuma sa medunarodnim učešcem, održanog od 17. do 19 . novembra 2016. godine na Medicinskom fakultetu Univerziteta u Novom Sadu. U radionice su bili uključeni studenti (neposredn učesnici radionica) i nastavnici (mentori i facilitatori) četiri studijska programa (medicine, farmacije, zdravstvene nege i stomatologije). Prva radionica prikazala je mogućnost pris
zbrinjavanju kritično obolelog/ povređenog (Slika 2).

Slika 2. Radionica 1 - zbrinjavanje povređenog motorcikliste

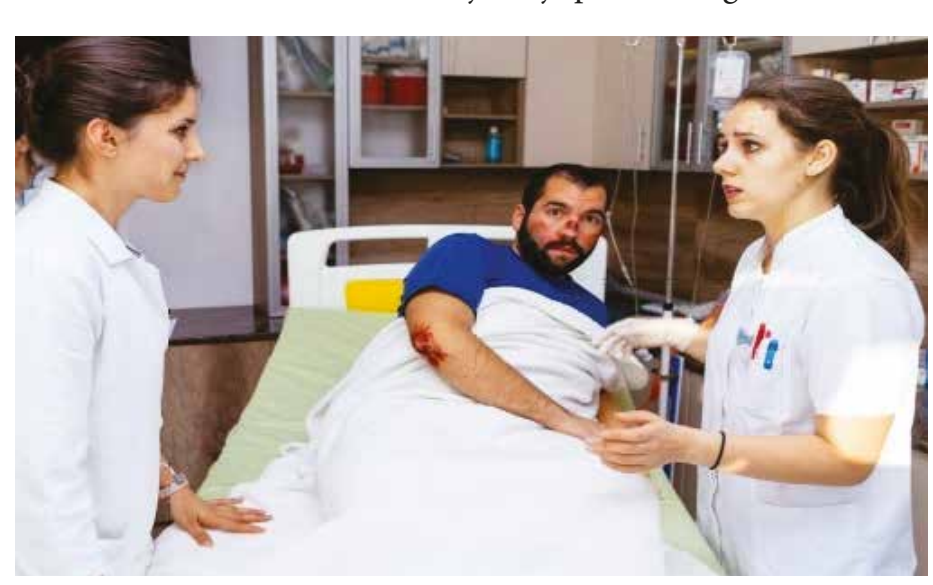

Na Slici 3. prikazan je detalj druge radionice sa tematikom: brinjavanje pacijenta obolelog od šećerne bolesti. Promocija oralnog zdravlia bila je tema treće radionice realizovane po principima IPO. (slika 4).

Nakon ovih i niza ostalih dvogodišnjih pripremnih aktivnosti od školske 2017/18. godine studenti, budući zdravstveni profesionalci sticaće svoje kvalifikacije i putem IPO na četiri univerziteta čiji je osnivač Republika (Beograd, Novi Sad, Kragujevac i Nǐ̌).

Slika 3. Radionica 2 - zbrinjavanje obolelog od šećerne bolesti

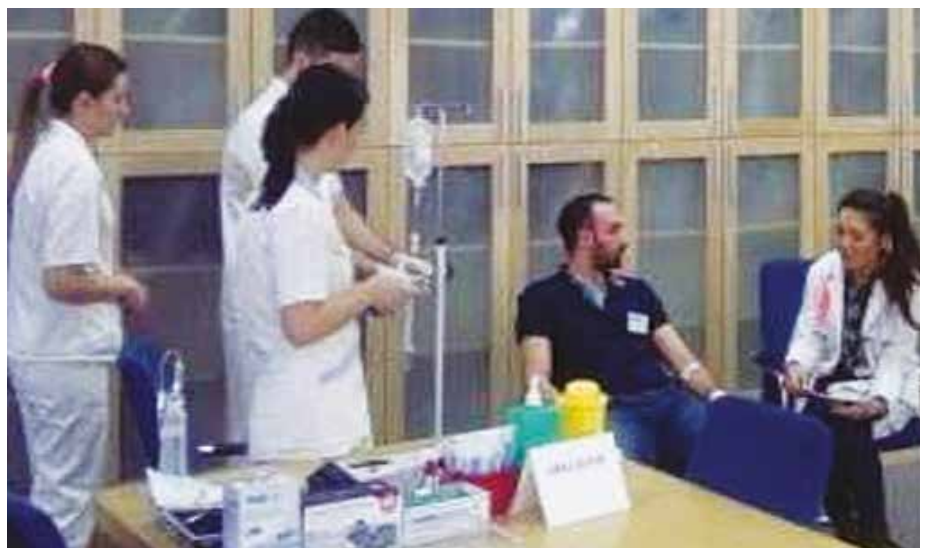

Slika 4. Radionica 3- promocija oralnog zdravlja

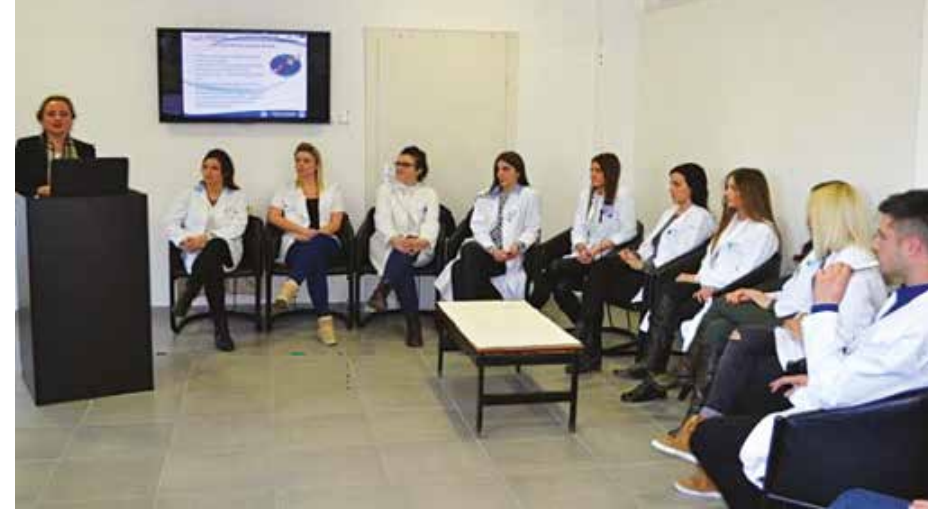

Kartoni predmeta, nastavni sadržaji, sadržaji IPO radionica (3 studije slučaja) i ostali metodicki i evaluacioni abu za sva cetiri univerziteta, a uvažavaju specifičnosti svih studijskih programa (medicine, farmacije, zd avstvene nege i stomatologije). Studenti fakulteta zdravstvenih nauka, buduci zdravstveni profesionalci nosioci su zdravstvene zaštite stanovništva i promoteri unapredenja zdravlja cele populacije.

Zato i zaslužuju da se njima i njihovom učenju posveti naročia pažnja. Razmatrajući benefite koje je IPO pružilo u međunarodsime svojih kvalitikacija pomocu ove obrazovne strategije, svakako bi trebalo da pruži znacajan doprinos kako njhovom profesional-

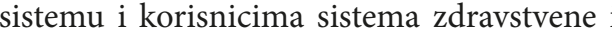
socijalne zaštite.

\section{LITERATURA:}

. Meleis AI. Interprofessional Education: A Summary of Reports and Barriers to Recommendations. J Nurs Scholarsh. 2016; 48(1):106x12.

2. Nandan M, Scott PA. Interprofessional practice and education: Holistic approaches to complex health care challenges. J Allied Health. 2014; 43(3):150x6

3. Barr H, Freeth D, Hammick M, Koppel I, Reeves S. The evidence base and recommendations for interprofessional education in health and social care. J Interprof Care. 2006; 20(1):75x8.

4. Bjorke G, Haavie E.N. Crossing boundaries: Implementing an interprofessional module into uniprofessional Bachelor programmes J Interprof Care. 2006; 20(6): 641-53.

5. Horsburgh M, Lamdin R, Williamson E. Multiprofessional learning: The attitudes of medical nursing and pharmacy students to shared learning. Med Educ. 2001; 35(9):876-83.

6. World Health Organization(WHO). World Health Report 2006: Working Together for Health. World Health Organization Study Group on Interprofessional Education and Collaborative Practice. World Health Organisation. Geneva, Switzerland; 2006.

7. World Health Organization Framework for Action on Interprofessional Educatione $\mathcal{}$ Collaborative Practice. World Health Organisation. Geneva, Switzerland; 2010.

8. Stone N. Coming in from the interprofessional cold in Australia. Aust Health Rev. 2007; 31(3):332-40.

9. Oandasan I, Reeves S. Key elements for interprofessional education. Part 1: The learner, the educator and the learning context.

J Interprof Care. 2005; 19(SUPPL. 1):21-38.

\section{AKTIVNOSTI KOMORE MEDICINSKIH SESTARA I ZDRAVSTVENIH TEHNIČARA SRBIJE U INTERESU SESTRINSTVA SRBIJE}

Radmila Ugrica, direktor KMSZTS

$\mathrm{N}$ (a) Komore, te izdavanje, obnavljanje i oduz-

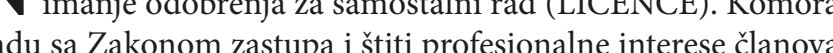
Komore u obavljanju profesije, donosi kodeks profesionalne etike i stara se o ugledu članova Komore odnosno o obavljanju poslov zdravstvene delatnosti u skladu sa Etičkim kodeksom.

Komora posreduje u sporovima članova Komore i korisnik zdravstvene zaštite, organizuje sudove časti radi utvrdivanja povre-

de profesionalne dužnosti i odgovornosti clanova Komore i izrič mere za te povrede te vodi imenik disciplinskih mera. Komor alja i druge poslove u skladu sa Zakonom.

Rea svake četiri godine. Svaki član Komore ima pravo da bira i bude biran. Komora ima 6 ogranaka: Ogranak Beograd, Ogranak Vojvodina, Ogranak Nis, Ogranak Kragujevac, Ogranak Užice Ogranak Kosovo i Metohija. Radom ogranaka rukovode Izvršni odbori Ogranaka. U 2017. godini Komora ima više od 100 hiljad

Komoru predstavlja i zastupa direktor Komore, koji rukovodi radom stručne službe u ograncima i centralnoj kancelariji Komore se nalazi u Beogradu, ulica Terazije 27/2.

Sigurna sam da mi, medicinske sestre i zdravstveni tehničari, kao jedna toliko brojna, bitna i humana profesija, imamo kapacitete da u drustvu i zdravstvenom sistemu zauzmemo mesto koje nam pripada, te da se za svoja prava, adekvatne nacine prevazilažnja teskoca i napredak izborimo kroz sve dostupne institucije Republe Srije. Move rada, bezbednije radno okružnje i priznate i prepoznate sve nivoe $\mathrm{U}$ mnogim zdravstvenim ustanovama Srbije još uvek je neadekvatna kadrovska selekcija na svim nivoima. Potrebno je izraditi jasne normative i standarde iz kojih slede sistematizacije radnih mesta sa ova kadrova.

Trenutno je u proceduri donošenje novog Zakona o zdravstenoj zasstiti u kojem do sad fakticki nije postojao pojam zdravstvene nege, pa je Konora medicinstih sestara i zdravstvenih tehnicara Sibije prillom izrade Nacrta Zakona o zdravstvenoj nezi insistirala na uvodenju zdravstvene nege i priznavanju svih nivoa suja i obrazovanja medicinskih sestara i zdravstvenih tehničara

Takođe u pripremi je i izrada Zakona o sestrinstvu kakav postoji u zemljama u okruženju, gde je veoma povoljno delovao na status i ugled medicinskih sestara i zdravstvenih tehničara u njihovim dravstvenim sistemim

Komora upravo da bi stimulisala medicinske sestre i zdravstvene tehničara za celoživotno obrazovanje ulaže znatna materijalna sredstva za formažno obra obrazovanje ulaže znat na ma za kontinuiranu medicinsku edukaciju.

Odliv stručnog kadra prema inostranstvu a samim tim nedostatak istog u našem zdravstvenom sistemu zahteva pobolǰšnje organizacije i uslova rada kako bi se medicinske sestre i zdravstve Težak i odgovoran posao, smenski rad i dežurstva trebalo bi budu adekvatno nagrađeni i vrednovani.

Takođe veliki problem je i brza prekvalifikacija iz drugih branši u medicinske sestre, čime se urušava ugled i nivo usluga a medicinske sestre i tehničar

Jedan od problema koji utiče na učestalu pojavu profesiona diche sprovođenje procesa zdravstvene nege i fizičke napore medicinskih 